\title{
Unraveling the intrafamilial correlations and heritability of tumor types in MEN1: a Groupe d'étude des Tumeurs Endocrines study
}

\author{
J Thevenon, A Bourredjem ${ }^{1,2}$, L Faivre, C Cardot-Bauters ${ }^{3}$, A Calender ${ }^{4}$, M Le Bras ${ }^{5}$, G Giraud $^{4}$, \\ P Niccoli ${ }^{6}$, M F Odou ${ }^{7}$, F Borson-Chazot ${ }^{8}$, A Barlier ${ }^{9,10}$, C Lombard-Bohas $^{11}$, E Clauser ${ }^{12,13}$, \\ A Tabarin ${ }^{14}$, E Pasmant ${ }^{15}$, O Chabre ${ }^{16}$, E Castermans ${ }^{17}$, P Ruszniewski ${ }^{18}$, J Bertherat ${ }^{19}$, \\ B Delemer $^{20}$, S Christin-Maitre ${ }^{21}$, A Beckers ${ }^{22}$, I Guilhem ${ }^{23}$, V Rohmer $^{24}$, B Goichot ${ }^{25}$, \\ P Caron ${ }^{26}$, E Baudin ${ }^{27}$, P Chanson ${ }^{28,29}$, L Groussin ${ }^{30,31}$, H Du Boullay ${ }^{32}$, G Weryha ${ }^{33}$, \\ P Lecomte ${ }^{34}$, F Schillo ${ }^{35}$, H Bihan ${ }^{36}$, F Archambeaud ${ }^{37}$, V Kerlan ${ }^{38}$, N Bourcigaux ${ }^{26}$,

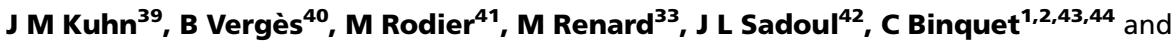 \\ P Goudet ${ }^{1,2,43,44,45}$
}

CHU de Dijon, Centre de Génétique et Centre de Référence Anomalies du Développement et Syndromes Malformatifs, University of Burgundy, EA4271 GAD, Dijon, France, ${ }^{1}$ INSERM, CIC1432, Dijon, France, ${ }^{2}$ Centre Hospitalier Universitaire de Dijon, Centre d'Investigation Clinique, éssais cliniques/épidémiologie clinique, Dijon France, ${ }^{3}$ Centre Hospitalier Régional et Universitaire de Lille, Service de Médecine interne et Endocrinologie, Clinique Marc Linquette, Lille, France, ${ }^{4}$ Hospices Civils de Lyon, Hôpital E. Herriot, Génétique moléculaire et clinique, Lyon, France, ${ }^{5}$ Centre Hospitalier Universitaire de Nantes, Clinique d'Endocrinologie, Nantes, France, ${ }^{6} \mathrm{APHM}$, service d'Oncologie Médicale, Institut Paoli-Calmettes, Université Aix-Marseille, Marseille, France, ${ }^{7} \mathrm{CHRU}$ de Lille, Service d'Hormonologie, Métabolisme-Nutrition, Oncologie, Pôle de Biologie Pathologie Génétique, Université de Lille2, Lille, France, ${ }^{8}$ Hospices Civils de Lyon et Université LYON1, Groupement hospitalier Est, Fédération d'Endocrinologie, Lyon, France, ${ }^{9} \mathrm{AP}-\mathrm{HM}$, Hôpital la Conception, Laboratoire de Biologie Moléculaire, Marseille, France, ${ }^{10}$ Aix-Marseille University, CRN2M UMR 7286-CNRS, Marseille, France, ${ }^{11}$ Hospices Civils de Lyon, Hôpital E. Herriot, Service d'Oncologie, Lyon, France, ${ }^{12}$ Université Paris-Descartes, Faculté de Médecine Paris-Descartes-Paris-V, UMR-S970, Paris, France, ${ }^{13} \mathrm{APHP}$, Hôpital Cochin, Laboratoire d'Oncogénétique, Paris, France, ${ }^{14}$ Centre Hospitalier Universitaire et Université de Bordeaux 2, Service d'Endocrinologie,Hôpital du Haut Levêque, Pessac, France, ${ }^{15}$ APHP, Hôpital Cochin, Service de Biochimie et de Génétique Moléculaire,Paris, France, ${ }^{16}$ Centre Hospitalier Universitaire de Grenoble, Service d'Endocrinologie, Diabète et Maladies métaboliques, Hôpital Michalon, Grenoble,France, ${ }^{17} \mathrm{Centre}$ Hospitalier Universitaire de Liège, Domaine Universitaire du Sart-Tilman, University of Liège, Laboratoire de génétique moléculaire, Liège, Belgium, ${ }^{18} \mathrm{APHP}$, Hôpital Beaujon et Université Paris 7 Denis Diderot, Service de Gastroentérologie-pancréatologie, Clichy, France, ${ }^{19} \mathrm{APHP}$, Hôpital Cochin, Université Paris Descartes, Sorbonne Paris Cité, University Paris-Diderot, Department of Endocrinology, Sorbonne Paris Cité, Paris, France, ${ }^{20}$ Department of Endocrinology, University Hospital of Reims, Reims, France, ${ }^{21}$ APHP, Groupement Hospitalier Universitaire Est, Hôpital Saint Antoine, Service d'Endocrinologie, Paris, France, ${ }^{22}$ Service d' Endocrinologie, Centre Hospitalier Universitaire de Liège, Université de Liège, Liège, Belgique, ${ }^{23}$ Department of Endocrinology, Diabetes and Nutrition, University Hospital of Rennes, Rennes, France, ${ }^{24}$ Endocrinology Department, Medicine University Hospital, Angers, LUNAM University, Université d'Angers, Angers, France, ${ }^{25}$ Hôpitaux universitaires de Strasbourg, Hôpital de Hautepierre, Service de Médecine interne endocrinologie et nutrition, Strasbourg, France, ${ }^{26} \mathrm{CHU}$ de Toulouse, Hôpital Larrey, Pôle Cardio-Vasculaire et Métabolique, Service d'Endocrinologie, Maladies Métaboliques, Nutrition, Toulouse, France, ${ }^{27}$ Institute Gustave Roussy, University of Paris-Sud, Department of Nuclear Medicine and Endocrine Oncology, Villejuif, France, ${ }^{28}$ University Paris-Sud, Faculté de Médecine Paris-Sud, UMR-S693, Le Kremlin-Bicêtre F-94276, France, ${ }^{29}$ APHP, Hôpital Bicêtre, Service d'Endocrinologie et des Maladies de la Reproduction, Le Kremlin-Bicêtre F-94276, France, ${ }^{30}$ Université Paris Descartes, Sorbonne Paris Cité, Faculté de médecine, Paris, France, ${ }^{31} \mathrm{APHP}$, Hopital Cochin, Department of Endocrinology, Paris, France, ${ }^{32}$ Centre Hospitalier Régional de Chambéry, Service d'endocrinologie, Chambéry, France, ${ }^{33}$ University Hospital of Nancy, Department of Endocrinology, Vandoeuvre-Les-Nancy, France, ${ }^{34}$ Unit of Endocrinology, Centre Hospitalier Régional Universitaire Tours, Tours, France, ${ }^{35}$ Département d'endocrinologie, métabolisme et diabétologie-nutrition, University of Franche-Comté, Hôpital Jean Minjoz, EA3920, U Besançon, France, ${ }^{36}$ APHP, Centre Hospitalo-Universitaire Avicenne, Service d'Endocrinologie, pôle des spécialités médicales, Bobigny, France, ${ }^{37}$ Department of Internal Medicine and Endocrinology, Hopital du Cluzeau, Limoges, France, ${ }^{38}$ Department of Endocrinology, Diabetes and Metabolic Diseases, CHU Brest, Hôpital de la Cavale Blanche, Université de Bretagne Occidentale, Brest, France, ${ }^{39}$ Department of Endocrinology, University Hospital of Rouen, Rouen, France, ${ }^{40}$ Centre Hospitalier Universitaire de Dijon, Hôpital du Bocage, Service d'Endocrinologie, Diabète et Maladies métaboliques, Dijon, France, ${ }^{41} \mathrm{CHRU}$ Nîmes, Hôpital Caremeau, Service des maladies Métaboliques et endocriniennes, Nîmes, France, ${ }^{42}$ Department of Endocrinology, Hopital de l'Archet, Nice, France, ${ }^{43}$ INSERM, U866, Dijon, France, ${ }^{44}$ University of Burgundy, U866 Dijon, France and ${ }^{45}$ Dijon University Hospital, Service de Chirurgie Endocrinienne, 21079 Dijon-Cédex, France

Correspondence should be addressed to P Goudet Email pierre.goudet@chu-dijon.fr (c) 2015 European Society of Endocrinology Printed in Great Britain
Published by Bioscientifica Ltd. 


\section{Abstract}

Background: MEN1, which is secondary to the mutation of the MEN1 gene, is a rare autosomal-dominant disease that predisposes mutation carriers to endocrine tumors. Most studies demonstrated the absence of direct genotype-phenotype correlations. The existence of a higher risk of death in the Groupe d'étude des Tumeurs Endocrines-cohort associated with a mutation in the JunD interacting domain suggests heterogeneity across families in disease expressivity. This study aims to assess the existence of modifying genetic factors by estimating the intrafamilial correlations and heritability of the six main tumor types in MEN1.

Methods: The study included 797 patients from 265 kindred and studied seven phenotypic criteria: parathyroid and pancreatic neuroendocrine tumors (NETs) and pituitary, adrenal, bronchial, and thymic (thNET) tumors and the presence of metastasis. Intrafamilial correlations and heritability estimates were calculated from family tree data using specific validated statistical analysis software.

Results: Intrafamilial correlations were significant and decreased along parental degrees distance for pituitary, adrenal and thNETs. The heritability of these three tumor types was consistently strong and significant with $64 \%$ (s.E.M. $=0.13 ; P<0.001)$ for pituitary tumor, $65 \%$ (s.E.M. $=0.21 ; P<0.001$ ) for adrenal tumors, and $97 \%$ (s.E.M. $=0.41 ; P=0.006$ ) for thNETs.

Conclusion: The present study shows the existence of modifying genetic factors for thymus, adrenal, and pituitary MEN1 tumor types. The identification of at-risk subgroups of individuals within cohorts is the first step toward personalization of care. Next generation sequencing on this subset of tumors will help identify the molecular basis of MEN1 variable genetic expressivity.

\section{Introduction}

MEN1 (OMIM 131100) is an autosomal dominant disorder secondary to MEN1 mutations that predispose carriers to endocrine tumors (1). The tumors mainly develop from endocrine tissues and may arise from parathyroid glands (90-100\%), the pancreas (50-70\%), pituitary gland (20-40\%), and adrenal glands (20-40\%), and at a lower frequency from the bronchi and thymus $(<15 \%)(2,3)$. Survival is limited in approximately $60 \%$ of patients because of MEN1 disease evolution (4). More than half of MEN1-related deaths are associated with tumors that are difficult to diagnose (5). These critical tumors, such as pancreatic neuroendocrine tumors (pNETs) or thymic tumors (thNETs), are characterized by frequent synchronous metastasis at diagnosis $(5,6,7,8,9)$. Familial clustering of specific tumors has been reported in the literature, as well as mild/late MEN1 phenotypes. Prolactinomas are specifically overrepresented in the Burin families, suggesting the existence of a founder effect (10). Gender is recurrently shown to modify tumor development in patients, notably for pituitary or thNETs $(8,11$, 12, 13). Additionally, several families from various ethnic origins are reported to present recurrent thNETs $(11,14,15)$. Nevertheless no direct genotype-phenotype correlation in MEN1 disease regarding the tumor types has ever been found $(16,17,18)$.

A recent genotype-phenotype study highlighted a global trend for intrafamilial correlations in disease expressivity (19). This previous study reported a higher risk of death in patients carrying MEN1 mutations affecting the JunD interacting domain. JunD, which regulates the transcriptional activity in interaction with the MENIN complex, is known to be pro-oncogenic in various cancer types. In families carrying mutations within the JunD interacting domain, patient survival was significantly lower, with a twofold increased risk of dying from MEN1-related cancers (19). The existence of intrafamilial correlations in MEN1 disease was also identified for most of the tumor types, and this hypothesis was in accordance with literature data (13). Nevertheless, the statistical approach was dedicated to genotype-phenotype association analysis and did not allow accurate estimations of intrafamilial correlations - that is to say, correlations according to the degree of the family relationship (i.e., parent-offspring, siblings, etc.). Indeed, one hypothesis is that people from the same family may share genetic variations accounting for shared 
intrafamilial tumor patterns. Besides, the progressive genetic dilution through generations within families (i.e., parental degree distance) should lead to the progressive disappearance of their influence together with the different expressivity (20). Thus, intrafamilial correlations should decrease with the degree of the relationship, which is the strongest between pairs of monozygotic twins, important between parents and children and between siblings, decreasing between second-degree relatives (namely, grandparents vs grandchildren, cousins) and third degree relatives (for instance, avuncular relatives, defined as uncle vs nephew), and finally tend toward zero for distant relatives in the same family. Tumor heritability should also be estimated for a better understanding of the genetic background of MEN1 tumors. Heritability estimation is a complementary genetic approach that aims to quantify the proportion of the phenotypic expression that is attributable to gene effects (21). Although intrafamilial correlations in MEN1 disease were suggested by rare observations reported in the literature, statistical estimates of intrafamilial correlations or heritability have never been provided in MEN1 disease. Therefore, the aims of this new genetic study were to quantify intrafamilial correlations and heritability among the six main MEN1-related tumors using the French MEN1/Groupe d'étude des Tumeurs Endocrines (GTE) cohort (19).

\section{Patients and methods}

\section{Population}

The GTE network for MEN1, created in February 1991, groups together clinical centers in France and Belgium and the four molecular genetics laboratories in charge of MEN1 diagnosis in these countries. In 2011, the GTE cohort for MEN1 included a total of 912 patients from 278 families. From these patients, we selected subjects with MEN1 mutations (Table 1). Overall, 823 patients had a genetic diagnosis. Among these, 26 patients (2.1\%) from 16 different families were excluded from the analysis because of missing data. Three families needed to be divided because of a missing common genealogical ancestor. The analysis finally included 797 patients from 265 kindred (Table 1).

A copy of each patient's file was obtained, anonymized, and stored at the Clinical Investigation Center of Dijon CHU. A case report form was created, filled in, and regularly updated from copies of the patients' medical files and regular visits by the surgeon in charge

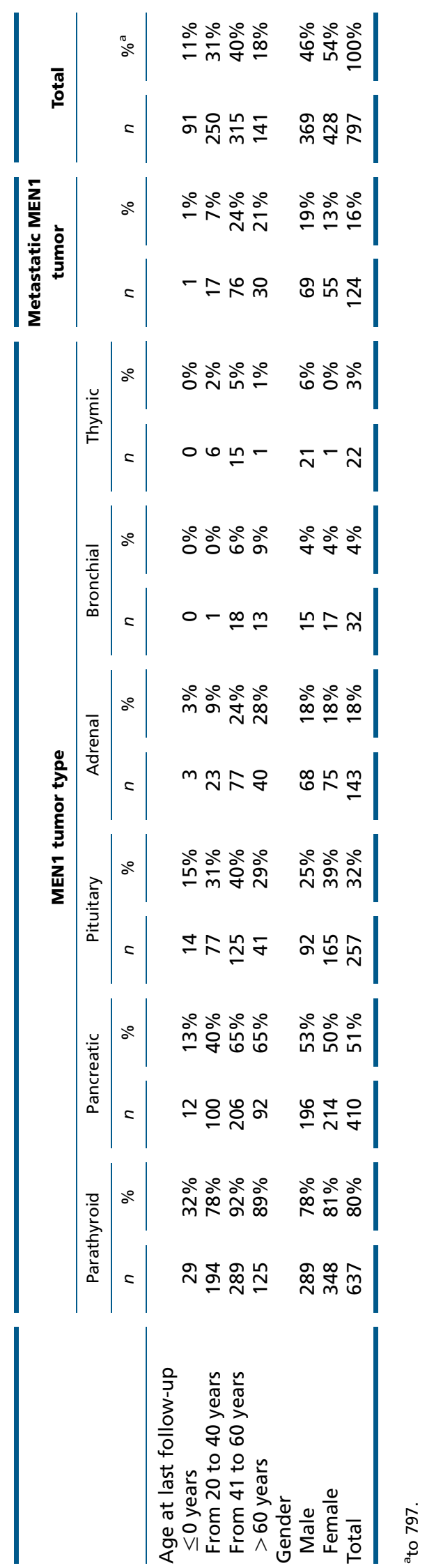


of the database (P G). This cohort was approved by the Consultative Committee on Treatment of Information in Health Research (CCTIRS), file number 12.364) and the Commission nationale de l'informatique et des libertés (CNIL, authorization number DR 2013-348). Written informed consent was not required, but patients were informed about their inclusion in the GTE cohort and had the right to withdraw their data.

\section{Phenotypes}

Seven phenotypic traits were studied, tumor aggressiveness (presence of metastasis) and six MEN1 lesion types: parathyroid, pNETs, pituitary, adrenal, bronchial, and thNETs. Descriptive analysis was performed according to the gender and the age at last follow-up. The follow-up duration and the age of first occurrence for each phenotypic criterion was described by medians and inter-quartiles range.

\section{Familial correlations and heritability}

Familial correlation coefficients, according to the degree of the family relationship (parent-offspring, siblings, avuncular, and cousin), were estimated using the FCOR program of Statistical Analysis for Genetic Epidemiology Version 6.0.1 (SAGE v6.0.1 Software) (22). Correlations were calculated between the residual trait values, after adjusting for gender and age at last follow-up. The asymptotic s.E.M. of a given correlation was estimated by using a second-order Taylor series expansion and replacing all correlation parameters with their respective estimates(20). As a prerequisite for this analysis, the homogeneity of correlations among subtypes (e.g., mother-offspring and father-offspring) and main types (e.g., parent-offspring) was tested; no intra-subtype heterogeneity was found.

Heritability for binary traitswas estimated through the liability threshold polygenic model as implemented in the Polygenic command of the Sequential Oligogenic Linkage Analysis Routines Version 6.6.2 (SOLAR v6.6.2) computer package $(21,23)$. This method uses a mixed effects model that incorporates fixed effects for known covariates (gender and age at last follow-up in the present study) and variance components for unknown genetic effects. Estimates were obtained by maximum likelihood methods and significance was determined by likelihood ratio tests. Interpretation was guided by the concordance between significant intrafamilial correlations among first-degree relatives (sibling and parents/offspring pairs) followed by
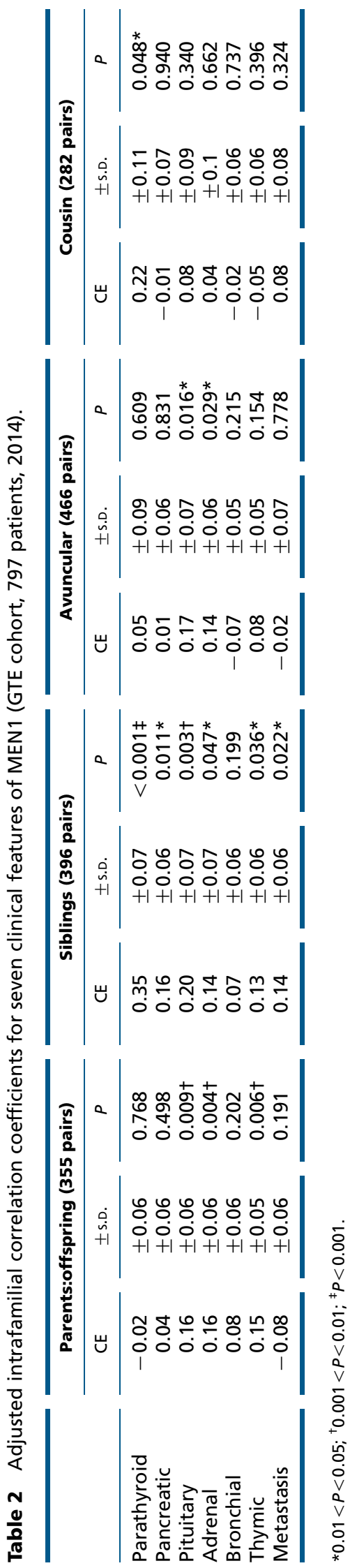
both a decrease in intrafamilial correlations with genetic dilution and strong and significant heritability estimates.

\section{Results}

Among the 265 families totaling 797 patients, kindred sizes ranged from 2 to 50 patients, with a median of 3 patients per kindred. Median follow-up was 46 years (inter-quartile range: 30-59 years). The prevalence of phenotypic criteria according to gender and age are shown in Table 1.

\section{Familial correlations}

Intrafamilial correlations were significant for 12 of the 28 tested conditions (Table 2, Fig. 1). In three different tumor types - namely the pituitary, adrenal, and thNETs intrafamilial correlation strength and significance decreased with genetic dilution. For pituitary tumors, the intrafamilial correlation estimate (CE) was strong and highly significant for parents/offspring and sibling, grouped in first-degree relatives $(\mathrm{CE}=0.16, P=0.009$ and $\mathrm{CE}=0.20, P=0.003$, respectively). It decreased but remained significant for second-degree relatives $(\mathrm{CE}=$ $0.17, P=0.016$ for avuncular). Finally, the intrafamilial CE was very weak and not significant for third-degree relatives ( $\mathrm{CE}=0.08, P=0.34$ for cousin). The same phenomenon was observed for adrenal and thNETs tumor types (Table 2, Fig. 1). This information is summarized in Fig. 1 in which two graphical patterns were presented. The top graph concerns pituitary, adrenal, and thNET tumor types with a strong and significant CE between first-degree relatives (parents/offsprings and sibling) followed by a decreasing in strength and significance along the genetic dilution (avuncular then cousin). Conversely, the other phenotypes (parathyroid, pancreatic, bronchial tumor types and metastasis) are presented in the bottom graph, with irregular evolution of the intrafamilial correlation strength and significance showing no evidence for the existence of genetic modifying factors for these MEN1 phenotypes.

\section{Heritability}

The heritability of these three tumor types was strong and significant: pituitary tumor heritability was of $64 \%$ (s.E.M. $=0.13 ; P<0.001$ ), adrenal tumor heritability, $65 \%$ (s.E.M. $=0.21 ; P<0.001$ ), and thNET heritability $97 \%$ (s.E.M. $=0.41 ; P=0.006$ ). There was no significant heritability for metastasis. Borderline heritability was observed for bronchial tumors. The heritability of parathyroid and pancreatic tumors was significant but this result was not confirmed by intrafamilial correlations (Table 3).
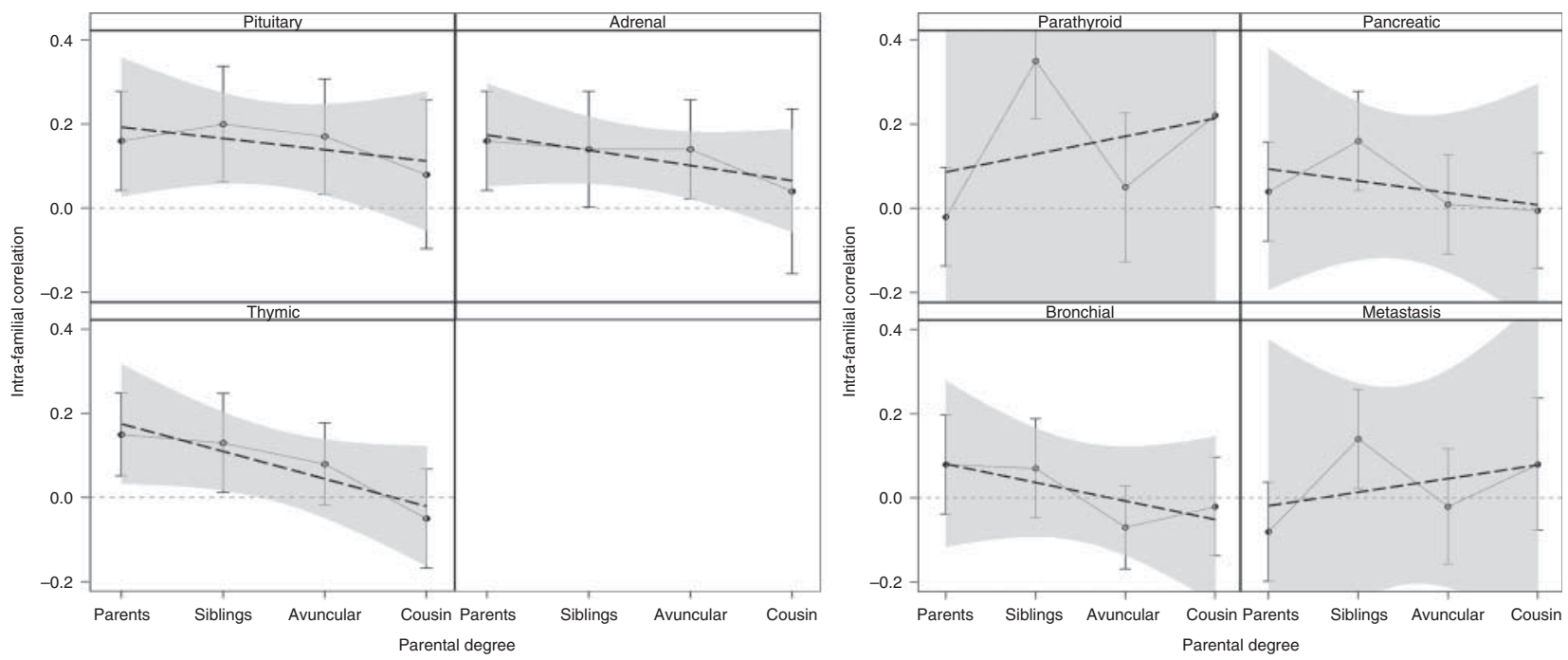

\section{Figure 1}

Representation of intrafamilial correlation estimates and decrease with genetic dilution within family pairs. Dots represent correlation estimates. Vertical lines represent their 95\% Cls. Dashed lines represent their regression trend and the shaded area their Cls. A genetic component is suspected in the case of a significant correlation at the parents:offspring degree followed by a correlation decrease with familial genetic dilution. 
Table 3 Heritability estimates for seven clinical features of MEN1 (GTE cohort, 797 patients, 2014).

\begin{tabular}{|c|c|c|c|}
\hline & \multicolumn{3}{|c|}{ Heritability } \\
\hline & Estimate & $( \pm$ s.D. $)$ & $P$ \\
\hline Parathyroid & $88 \%$ & $( \pm 0.18)$ & $<0.001$ \\
\hline Pancreatic & $37 \%$ & $( \pm 0.14)$ & 0.001 \\
\hline Pituitary & $64 \%$ & $( \pm 0.13)$ & $<0.001$ \\
\hline Adrenal & $65 \%$ & $( \pm 0.21)$ & $<0.001$ \\
\hline Bronchial & $60 \%$ & $( \pm 0.35)$ & 0.037 \\
\hline Thymic & $97 \%$ & $( \pm 0.41)$ & 0.006 \\
\hline Metastasis & $19 \%$ & $( \pm 0.16)$ & 0.104 \\
\hline
\end{tabular}

\section{Discussion}

The estimation of the genetic components of MEN1 disease expressivity requires a dedicated statistical approach on a large cohort of patients. This estimation has become possible using one of the largest MEN1 cohorts, totaling 797 patients from 265 kindred. The intrafamilial correlation and trait heritability for six tumor types and metastasis were calculated and a significant genetic component was evidenced in three of them, namely, thNETs, pituitary, and adrenal tumors. In addition to mutations affecting the JunD interacting domain, the aforementioned results suggest the existence of additional genetic markers allowing the definition of at-risk groups of individuals (18).

The MEN1 GTE cohort has already been described and is deemed representative of MEN1 disease in Western Europe (18). There were no major differences in terms of lesion prevalence compared with the independent German and Netherlands cohorts $(18,24)$. The GTE cohort had a median follow-up of 47 years and thus allowed us to study the age-dependent expressivity of MEN1 disease with time-to-event techniques $(4,19)$. During this analysis, we showed intrafamilial correlations without direct phenotype-genotype correlations. In addition, we reported the first arguments for the implication of genetic factors able to modify MEN1 disease expression. Indeed, a global trend for heterogeneity across families was observed, suggesting the existence of other genetic factors able to modify MEN1 disease expressivity, as expected since the discovery of the MEN1 gene $(13,14,19)$. These preliminary results were a first step toward unraveling the genetic determinants of MEN1 disease expressivity. Estimation of a trait's heritability in a familial disease with variable expressivity depends on the partitioning of a trait into genetic and environmental factors (25). The balance between genes and environmental effects in the phenotypic variance in MEN1 traits was estimated with a robust statistical approach previously applied to neurofibromatosis type $1(26,27,28)$. Two complementary methods were used to quantify intrafamilial correlations. As expected from the existence of familial clusters of thNETs in the literature $(11,12,14)$, a strong genetic component was identified regarding thNETs. While these tumors are diagnosed in 5-7\% of MEN1 patients, the first series of genotyped patients with thNETs revealed that $15 / 150$ cases were familial $(3,11,12,14,18)$. The pedigree shown in Fig. 2 consistently highlights the pseudodominant inheritance of thNETs in a familial cluster (heritability estimate 97\%, s.E.M.=0.47). No correlation decrease was found for parathyroid and pancreatic tumors and no genetic dilution was noted. The heritability of pNETs was significant but weak (37\%). This result may be related to the heterogeneity of pNET subtypes. However, the statistical power was insufficient to test each subtype separately. In contrast, parathyroid tumor heritability was strong (Table 3), but this finding may merely reflect the high prevalence of parathyroid tumors in MEN1 patients (637/797 patients, $80 \%$ of the GTE cohort).

Besides the thNET results, both intrafamilial correlations and heritability were significant regarding pituitary and adrenal tumors. These unsuspected results may have direct clinical implications. Current recommendations related to the detection of these tumors advise regular workups and starting a follow-up program at 10 years old for pituitary and adrenal tumors and 15 years old for thNETs $(29,30)$. Nevertheless, real life shows that updated recommendations are not always correctly applied for

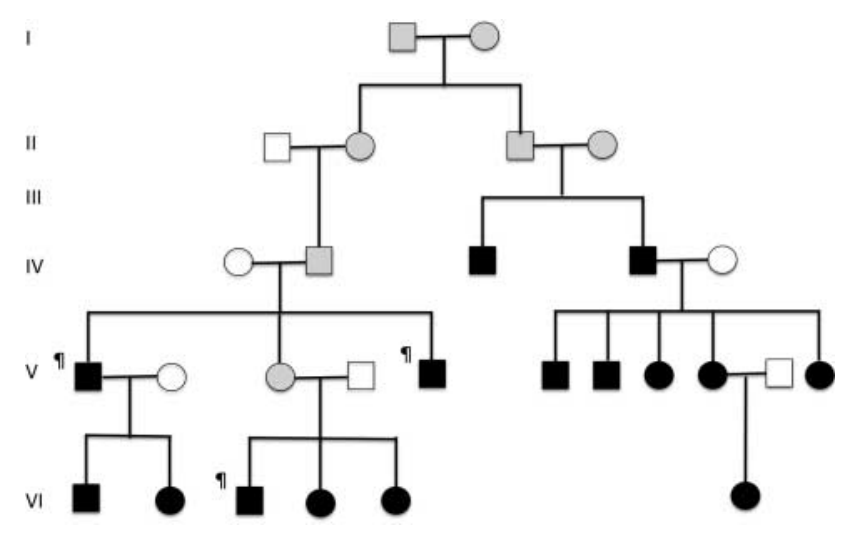

\section{Figure 2}

Example of a family tree harboring an aggregate of three thymic tumors ( $\uparrow$ ) among the 15 MEN1 carriers (black boxes). Known individual from the family but without available clinical information are represented with gray boxes. 
many good and bad reasons. This study reminds us that pituitary adenomas, adrenal tumors, and thNETs must be regularly screened for, particularly among relatives of patients affected by these tumors. This strategy is well known for thNETs because thNET clusters were evidenced early. The right imaging tool to detect this tumor is still debated because yearly CT scans of the chest could be harmful, but it is known and accepted that we must pay particular attention to the relatives of patients with thNETs $(11,12,14,15)$. Pituitary adenomas and adrenal tumors are underdiagnosed tumor types in MEN1. A recent study showed that young men between 15 and 20 years old with MEN1 may harbor large pituitary adenomas, and the clinical experience of the GTE cohort shows that compliance with follow-up is not easy at this age (30). Therefore, this group at risk must be particularly screened when pituitary adenomas have already been found in the same family. Adrenal tumor screening should be carefully performed when this lesion already exists in the family. There are several reasons why adrenal tumors may be under-evaluated during follow-up: the prevalence is low and adrenal tumors are present in only $24 \%$ of patients aged 40-60 years; these tumors are rarely aggressive; and abdominal imaging usually focuses on the pancreas and liver because pNETs are the main challenge for abdominal surgery in terms of cancer development and spread.

To conclude, the current recommendations for screening and follow-up regarding thNET, pituitary, and adrenal tumors must be strictly followed among relatives of affected patients. This study is an additional step toward unraveling the genetic contribution to variable expressivity of MEN1 disease and a more personalized follow-up for MEN1 families. As far as genetic research is concerned, families with multiple occurrences of these tumor types should be the best candidates for the identification of genetic factors able to modify MEN1 expressivity.

\section{Declaration of interest}

The authors declare that there is no conflict of interest that could be perceived as prejudicing the impartiality of the research reported.

\section{Funding}

This work was supported by a grant from the University Hospital of Dijon, the Regional council of Burgundy by the Regional action plan for the innovation 2011, and the Groupe d'étude des Tumeurs Endocrines.

\section{Acknowledgements}

Many thanks to $\mathrm{P}$ Bastable for the English revision of the manuscript and A Costa and S Vinault for the data management of the GTE cohort of MEN1.
The authors would also like to thank the members of the GTE: C Ajzenberg, J J Altman, T Aparicio, J R Attali, C Badet, J Barbier, M Barthet, B Bauduceau, H Becheur, P Bernades, X Bertagna, J Bertherat, O Blétry, P Boissel, J M Boyaval, L Bresler, J F Bretagne, J Bringer, H Brixi-Benmansour, L Brunaud, J Burger, G Cadiot, A Calender, P Carenco, B Carnaille, B Cathebras, M Celerier, R Cohen, G Chabrier, D Chadenas, P Chaffanjon, D Charitanski, J A Chayvialle, C Colmar Montiel, J M Comas, B Conte Devolx, A Cortot, E Cosson, P D'Anella, P Darsy, F Delecourt, J Denis, C Derrien, D Dewailly, A S Dramais, C Droumaguet, C Dubost, B Emperauger-Beauvais, P Emy, S Gauthier, A P GimenezRoqueplo, D Goldfain, M Gosselin, F Grunenberger, A M Guedj, P J Guillausseau, P Hamon, P J Jaquet, C Jublanc, B Knebelmann, J L Kraimps, A Krivtzky, Lagarde F, J D Lalau, J J Legros, D Levoir, N Lévy-Bohbot, Lifante J C, B Maizeray-Cailliau, D Malet, M Malinski, Maroy B, C Mathe, M Mathonnet, D Melliere, $F$ Ménégaux, E H Metman, M Meurisse, E Mirallié E, R Modigliani, M Monsaingeon, C Naouri, C Oliver, F Olivier, J Orgiazzi, L Osmak, M Parneix, C Partenski, F Pattou, J L Peix, F Penfornis, A Pradignac, C Pouget, M Pugeat, M L Raffin-Sanson, M Rodier, $\mathrm{P}$ Roger, $\mathrm{P}$ Rougier, H Rousset, J Roy, E Sarfati, J L Schlienger, M Schlumberger, P Selvais, P Seve, D Simon, I Sobhani, O Soubrane, J C Soule, P Thieblot, C Thivolet, P Thomopoulos, Triponez F, P Valensi, M C Vantighem, M F Verger, O Verier-Mine, E Verlet, M Veyrac, B Vialettes, R Viard, S Walter, A Warnet,

B Wechsler, J L Wemeau, B Woehl-Kremer, J Young, and Association Française de Chirurgie Endocrinienne (AFCE) members.

\section{References}

1 Wermer P. Duality of pancreatogenous peptic ulcer. New England Journal of Medicine 1968278 397-398.

2 Brandi ML. Multiple endocrine neoplasia type 1. Reviews in Endocrine \& Metabolic Disorders 20001 275-282. (doi:10.1023/A:1026562217102)

3 de Laat JM. Natural course and survival of neuroendocrine tumors of thymus and lung in MEN1 patients. Journal of Clinical Endocrinology and Metabolism 201499 3325-3333. (doi:10.1210/jc.2014-1560)

4 Goudet P. Risk factors and causes of death in MEN1 disease. A GTE (Groupe d'Etude des Tumeurs Endocrines) cohort study among 758 patients. World Journal of Surgery 201034 249-255. (doi:10.1007/ s00268-009-0290-1)

5 Triponez F, Dosseh D, Goudet P, Cougard P, Bauters C, Murat A, Cadiot G, Niccoli-Sire P, Chayvialle J-A, Calender A et al. Epidemiology data on 108 MEN 1 patients from the GTE with isolated nonfunctioning tumors of the pancreas. Annals of Surgery 2006243 265-272. (doi:10.1097/01.sla.0000197715.96762.68)

6 Lévy-Bohbot N, Merle C, Goudet P, Delemer B, Calender A, Jolly D, Thiéfin G, Cadiot G \& Groupe des Tumeurs Endocrines. Prevalence, characteristics and prognosis of MEN 1-associated glucagonomas, VIPomas, and somatostatinomas: study from the GTE (Groupe des Tumeurs Endocrines) registry. Gastroentérologie Clinique et Biologique 200428 1075-1081. (doi:10.1016/S0399-8320(04)95184-6)

7 Triponez F, Goudet P, Dosseh D, Cougard P, Bauters C, Murat A, Cadiot G, Niccoli-Sire P, Calender A, Proye Ch et al. Is surgery beneficial for MEN1 patients with small ( $<$ or $=2 \mathrm{~cm}$ ), nonfunctioning pancreaticoduodenal endocrine tumor? An analysis of 65 patients from the GTE World Journal of Surgery 200630 654-662. ; discussion 663-664. (doi:10.1007/s00268-005-0354-9)

8 Goudet P, Bonithon-Kopp C, Murat A, Ruszniewski P, Niccoli P, Ménégaux F, Chabrier G, Borson-Chazot F, Tabarin A, Bouchard P et al. Gender-related differences in MEN1 lesion occurrence and diagnosis: a cohort study of 734 cases from the Groupe d'etude des Tumeurs Endocrines. European Journal of Endocrinology/European Federation of Endocrine Societies 2011165 97-105. (doi:10.1530/EJE-10-0950)

9 Gatta-Cherifi B, Chabre O, Murat A, Niccoli P, Cardot-Bauters C, Rohmer V, Young J, Delemer B, Du Boullay H, Verger MF et al. Adrenal involvement in MEN1. Analysis of 715 cases from the 
Groupe d'etude des Tumeurs Endocrines database. European Journal of Endocrinology / European Federation of Endocrine Societies 2012166 269-279. (doi:10.1530/EJE-11-0679)

10 Hao W, Skarulis MC, Simonds WF, Weinstein LS, Agarwal SK, Mateo C, James-Newton L, Hobbs GR, Gibril F, Jensen RT et al. Multiple endocrine neoplasia type 1 variant with frequent prolactinoma and rare gastrinoma. Journal of Clinical Endocrinology and Metabolism 200489 3776-3784. (doi:10.1210/jc.2003-031511)

11 Goudet P, Murat A, Cardot-Bauters C, Emy P, Baudin E, du Boullay Choplin H, Chapuis Y, Kraimps J-L, Sadoul J-L \& Tabarin A. GTE network (Groupe des Tumeurs Endocrines). Thymic neuroendocrine tumors in multiple endocrine neoplasia type 1: a comparative study on 21 cases among a series of 761 MEN1 from the GTE (Groupe des Tumeurs Endocrines). World Journal of Surgery 200933 1197-1207. (doi:10.1007/s00268-009-9980-y)

12 Sakurai A, Imai T, Kikumori T, Horiuchi K, Okamoto T, Uchino S, Kosugi S, Suzuki S, Suyama K, Yamazaki M et al. Thymic neuroendocrine tumour in multiple endocrine neoplasia type 1: female patients are not rare exceptions. Clinical Endocrinology 201378 248-254. (doi:10.1111/j.1365-2265.2012.04467.x)

13 Lips CJ, Dreijerink KM \& Höppener JW. Variable clinical expression in patients with a germline MEN1 disease gene mutation: clues to a genotype-phenotype correlation. Clinics 201267 49-56. (doi:10.6061/ clinics/2012(Sup01)10)

14 Teh BT, Hayward NK, Walters MK, Shepherd JJ, Wilkinson S, Nordenskjold M \& Larsson C. Genetic studies of thymic carcinoids in multiple endocrine neoplasia type 1. Journal of Medical Genetics 199431 261-262. (doi:10.1136/jmg.31.3.261)

15 Ferolla P, Falchetti A, Filosso P, Tomassetti P, Tamburrano G, Avenia N, Daddi G, Puma F, Ribacchi R, Santeusanio F et al. Thymic neuroendocrine carcinoma (carcinoid) in multiple endocrine neoplasia type 1 syndrome: the Italian series. Journal of Clinical Endocrinology and Metabolism 200590 2603-2609. (doi:10.1210/jc.2004-1155)

16 Kouvaraki MA, Lee JE, Shapiro SE, Gagel RF, Sherman SI, Sellin RV, Cote GJ \& Evans DB. Genotype-phenotype analysis in multiple endocrine neoplasia type 1. Archives of Surgery 2002137 641-647. (doi:10.1001/archsurg.137.6.641)

17 Wautot V, Vercherat C, Lespinasse J, Chambe B, Lenoir GM, Zhang CX, Porchet N, Cordier M, Béroud C \& Calender A. Germline mutation profile of MEN1 in multiple endocrine neoplasia type 1: search for correlation between phenotype and the functional domains of the MEN1 protein. Human Mutation 200220 35-47. (doi:10.1002/humu. 10092)

18 Machens A, Schaaf L, Karges W, Frank-Raue K, Bartsch DK, Rothmund M, Schneyer U, Goretzki P, Raue F \& Dralle H. Age-related penetrance of endocrine tumours in multiple endocrine neoplasia type 1 (MEN1): a multicentre study of 258 gene carriers. Clinical Endocrinology 200767 613-622. (doi:10.1111/j.1365-2265.2007. 02934.x)
19 Thevenon J, Bourredjem A, Faivre L, Cardot-Bauters C, Calender A, Murat A, Giraud S, Niccoli P, Odou M-F, Borson-Chazot F et al. Higher risk of death among MEN1 patients with mutations in the JunD interacting domain: a Groupe d'etude des Tumeurs Endocrines (GTE) cohort study. Human Molecular Genetics 201322 1940-1948. (doi:10.1093/hmg/ddt039)

20 Keen KJ \& Elston RC. Robust asymptotic sampling theory for correlations in pedigrees. Statistics in Medicine 200322 3229-3247. (doi:10.1002/sim.1559)

21 Duggirala R, Williams JT, Williams-Blangero S \& Blangero J. A variance component approach to dichotomous trait linkage analysis using a threshold model. Genetic Epidemiology 199714 987-992. (doi:10.1002/ (SICI) 1098-2272(1997)14:6 < 987::AID-GEPI71 > 3.0.CO;2-G)

22 SAGE 2012 Statistical Analysis for Genetic Epidemiology, Release 6.3:http://darwin.cwru.edu

23 Almasy L \& Blangero J. Multipoint quantitative-trait linkage analysis in general pedigrees. American Journal of Human Genetics 199862 1198-1211. (doi:10.1086/301844)

24 De Laat JM, Tham E, Pieterman CRC, Vriens MR, Dorresteijn JAN, Bots ML, Nordenskjöld M, van der Luijt RB \& Valk GD. Predicting the risk of multiple endocrine neoplasia type 1 for patients with commonly occurring endocrine tumors. European Journal of Endocrinology/European Federation of Endocrine Societies 2012167 181-187. (doi:10.1530/EJE-120210)

25 Visscher PM, Hill WG \& Wray NR. Heritability in the genomics era concepts and misconceptions. Nature Review Genetics 20089 255-266. (doi:10.1038/nrg2322)

26 Easton DF, Ponder MA, Huson SM \& Ponder BA. An analysis of variation in expression of neurofibromatosis (NF) type 1 (NF1): evidence for modifying genes. American Journal of Human Genetics 199353 305-313.

27 Szudek J, Joe H \& Friedman JM. Analysis of intrafamilial phenotypic variation in neurofibromatosis 1 (NF1). Genetic Epidemiology 200223 150-164. (doi:10.1002/gepi.1129)

28 Sabbagh A, Pasmant E, Laurendeau I, Parfait B, Barbarot S, Guillot B, Combemale P, Ferkal S, Vidaud M, Aubourg P et al. Unravelling the genetic basis of variable clinical expression in neurofibromatosis 1 . Human Molecular Genetics 200918 2768-2778. (doi:10.1093/hmg/ ddp212)

29 Thakker RV, Newey PJ, Walls GV, Bilezikian J, Dralle H, Ebeling PR, Melmed S, Sakurai A, Tonelli F, Brandi ML et al. Clinical practice guidelines for multiple endocrine neoplasia type 1 (MEN1). Journal of Clinical Endocrinology and Metabolism 201297 2990-3011. (doi:10.1210/ jc.2012-1230)

30 Goudet P, Dalac A, Le Bras M, Cardot-Bauters C, Niccoli P, LévyBohbot N, du Boullay H, Bertagna X, Ruszniewski P, Borson-Chazot F et al. MEN1 disease occurring before 21 years old. A 160-patient cohort study from the GTE (Groupe d'étude des Tumeurs Endocrines). Journal of Clinical Endocrinology and Metabolism 2015160 jc20143659. (doi:10.1210/jc.2014-3659)

Received 10 July 2015

Revised version received 16 September 2015

Accepted 21 September 2015 